\title{
Endoscopic incision and balloon dilation using the rendezvous technique for complete anastomotic obstruction after rectal low-anterior resection
}

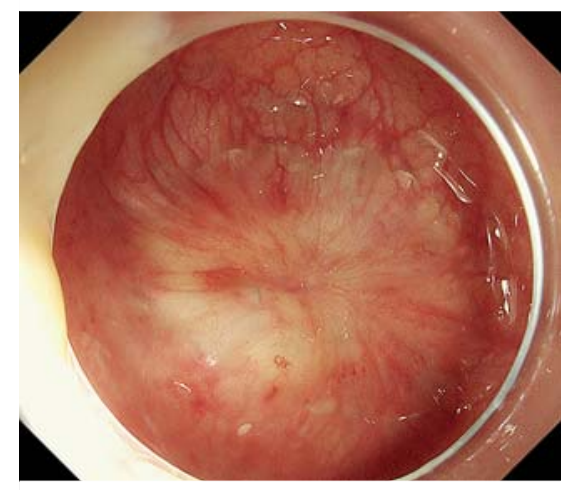

- Fig. 1 Colonoscopic view before planned surgical stoma closure showing complete anastomotic obstruction after rectal low-anterior resection.

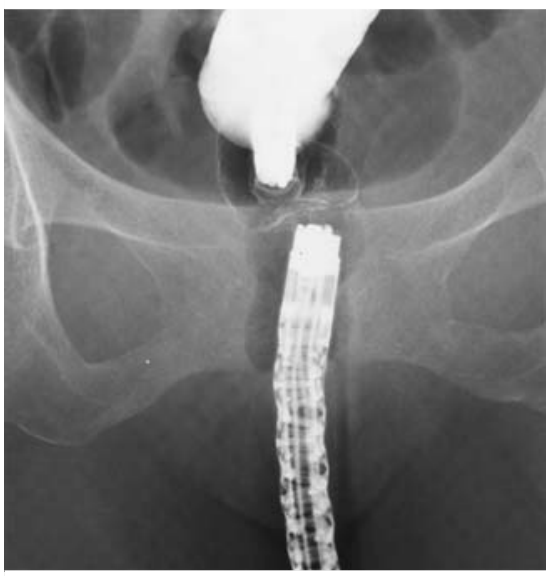

- Fig. 2 Fluoroscopic image showing the use of two endoscopes, one passed through the distal loop ileostomy site and the other inserted transanally, to approach the obstruction site, with no evidence of flow of contrast agent sprayed from the trans-stomal endoscope to the anorectal side.

Anastomotic stenosis, a major complication after low-anterior resection, can usually be treated by endoscopic balloon dilation [1,2]. However, endoscopic management is challenging in the presence of a complete obstruction because an endoscope and other devices cannot be passed through the obstruction. Com-

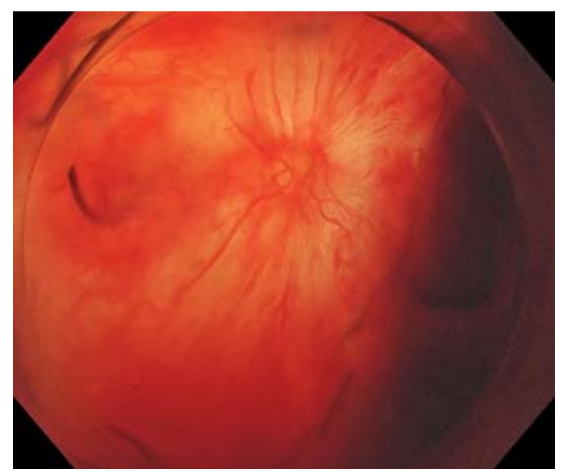

- Fig. 3 Endoscopic image from the anal side of the obstruction showing evidence of transillumination from the trans-stomal endoscope across the septum, suggesting that the obstruction was membranous.

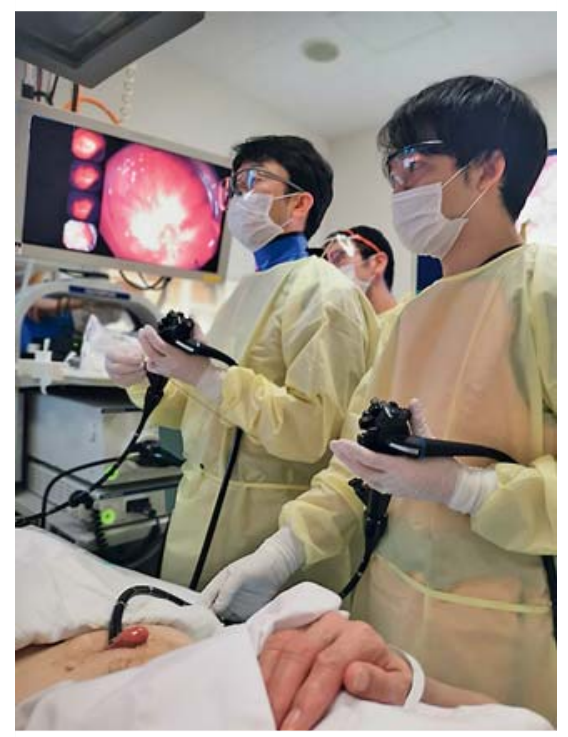

- Fig. 4 Photograph during the procedure showing the endoscopist on the left making an incision at the obstruction site from the anal side, while the endoscopist on the right confirms the incision site from the oral side.

bined endoscopic incision and balloon dilation has reportedly been useful for treating complete rectal anastomotic obstruction [3]. If the patient has a stoma with double orifices, a simultaneous antegrade-retrograde approach to the

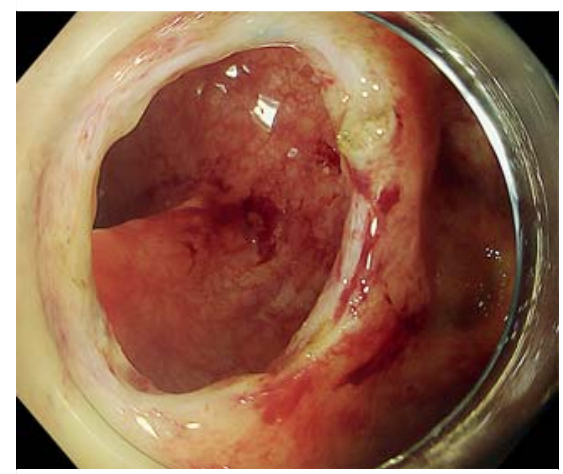

- Fig. 5 Endoscopic view showing complete recanalization of the obstruction following endoscopic balloon dilation.

obstructed anastomosis using two endoscopes may be feasible, a method known as the "rendezvous technique"[4].

A woman in her 60 s underwent laparoscopic rectal low-anterior resection and a diverting loop ileostomy after previous endoscopic submucosal dissection (ESD) for early rectal cancer. Stoma closure was scheduled to be performed 7 months post-surgery, but a colonoscopy performed for preoperative evaluation revealed complete obstruction of the rectal anastomosis (> Fig.1). Accordingly, endoscopic intervention was attempted for this obstruction.

An endoscope (PCF-H290TI; Olympus Co., Tokyo, Japan) with a distal attachment (D-201-11804; Olympus) was passed through the distal loop ileostomy site until it reached the oral side of the obstruction site. Simultaneously, another endoscope (PCF-H290ZI; Olympus) with a distal attachment (D-20113404; Olympus) was inserted transanally. Although contrast agent sprayed through the trans-stomal endoscope did not flow to the anorectal side ( $>$ Fig. 2 ), transillumination from the trans-stomal endoscope could be seen across the septum ( $>$ Fig.3), suggesting the obstruction was membranous. The obstruction site was incised from the anal 


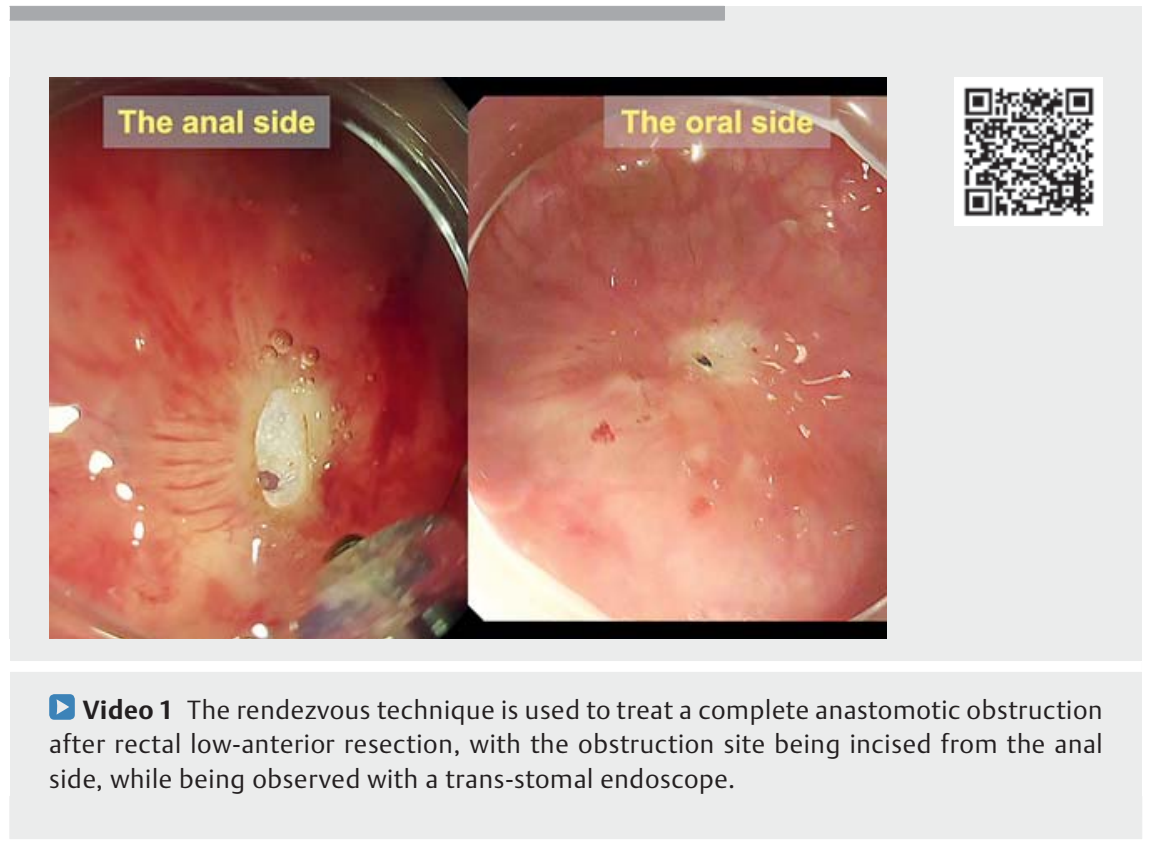

side using an electrosurgical endoknife (ISSEN; Kaneka Co., Tokyo, Japan) while the incision site was confirmed from the oral side using the rendezvous technique ( Fig.4). After a small aperture was created, a controlled radial expansion balloon (Boston Scientific, Marlborough, Massachusetts, USA) was inserted and endoscopic balloon dilation was performed. The obstruction was completely recanalized without adverse events ( Fig. 5; - Video 1).

Endoscopy_UCTN_Code_TTT_1AQ_2AF

\section{Acknowledgments}

We thank Angela Morben, DVM, ELS, from Edanz Group (https://en-author-services.edanzgroup. $\mathrm{com} / \mathrm{ac}$ ), for editing a draft of this manuscript.

\section{Competing interests}

Yoji Takeuchi received honoria from Olympus.
The authors

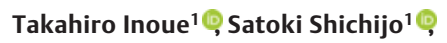
Masayoshi Yasui $^{2}$, Yoji Takeuchi ${ }^{1}$, Tomoki Michida ${ }^{1}$, Ryu Ishihara ${ }^{1}$

1 Department of Gastrointestinal Oncology, Osaka International Cancer Institute, Osaka, Japan

2 Department of Surgery, Osaka International Cancer Institute, Osaka, Japan

\section{Corresponding author}

\section{Satoki Shichijo, MD, PhD}

Department of Gastrointestinal Oncology, Osaka International Cancer Institute, 3-1-69, Otemae, Chuo-ku, Osaka 541-8567, Japan 7satoki@oici.jp

[1] Viriglio C, Consentino S, Favara C et al. Endoscopic treatment of postoperative colonic strictures using an achalasia dilator: shortterm and long-term results. Endoscopy 1995; 27: 219-222

[2] Di Giorgio P, De Luca L, Rivellini G et al. Endoscopic dilation of benign colorectal anastomotic stricture after low anterior resection: a prospective comparison study of two balloon types. Gastrointest Endosc 2004; 60: 347-350

[3] Yuan X, Liu W, Ye L et al. Combination of endoscopic incision and balloon dilation for treatment of a completely obstructed anastomotic stenosis following colorectal resection: A case report. Medicine (Baltimore) 2019; 98: e16292

[4] Kaushik N, Rubin J, McGrath K. Treatment of benign complete colonic anastomotic obstruction by using an endoscopic rendezvous technique. Gastrointest Endosc 2006; 63: $727-730$

Bibliography

\section{Endoscopy 2022; 54: E90-E91}

DOI 10.1055/a-1393-5165

ISSN 0013-726X

published online 15.3.2021

(c) 2021. Thieme. All rights reserved.

Georg Thieme Verlag KG, Rüdigerstraße 14,

70469 Stuttgart, Germany

\section{ENDOSCOPY E-VIDEOS}

https://eref.thieme.de/e-videos

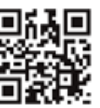

Endoscopy E-Videos is an open access online section, reporting on interesting cases and new techniques in gastroenterological endoscopy. All papers include a high quality video and all contributions are freely accessible online. Processing charges apply (currently EUR 375), discounts and wavers acc. to HINARI are available.

This section has its own submission website at https://mc.manuscriptcentral.com/e-videos 